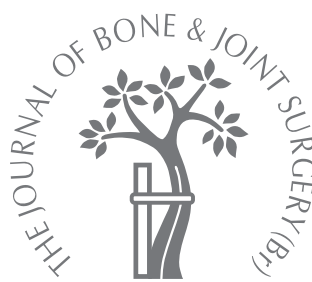

O. Reigstad,

P. Siewers

From the University of Oslo, Oslo,

Norway
O. Reigstad, MD,

Orthopaedic Surgeon

Orthopaedic Department

Rikshospitalet, N-0027 Oslo

Norway.

In P. Siewers, MD, Orthopaedic

Surgeon

Orthopaedic Department

Martina Hansens Hospital, N-

1306 Baerum, Norway.

Correspondence should be sent to $\mathrm{Dr}$ O. Reigstad; e-mail: ole.reigstad@rikshospitalet.no

(C)2008 British Editorial Society of Bone and Joint Surgery doi:10.1302/0301-620X.90B2. $20038 \$ 2.00$

$J$ Bone Joint Surg $[B r]$ 2008;90-B:225-7.

Received 2 August 2007;

Accepted 17 September 2007

CASE REPORT

\title{
A total hip replacement infected with mycobacterium bovis after intravesicular treatment with Bacille-Calmette-Guérin for bladder cancer
}

An 86-year-old male presented with a loose total hip replacement (THR) ten years after implantation. At revision for anticipated aseptic loosening, watery pus was found in the joint and Bacille-Calmette-Guérin (BCG) was seen on culture. The bacterial strain was identified and was identical to the BCG used in the intravesicular treatment of superficial bladder carcinoma in this patient ten months earlier. After revision he received a full course of antituberculous treatment.

The clinical and radiological results were excellent after follow-up for $\mathbf{3 0}$ months with his uncemented THR showing satisfactory incorporation. His inflammatory markers were normal and his Harris hip score was $\mathbf{9 5}$ points.

The diagnosis of a tuberculous infection can be easily missed, but must be considered, especially if sterile pus is encountered.

Revision of a total joint replacement for suspected aseptic loosening will occasionally reveal unexpected infection. ${ }^{1}$ Identification of the micro-organism has implications for treatment. Worldwide, tuberculosis is a major infectious disease and an increase in its incidence is anticipated in industrialised countries. $^{2}$ We report an unusual case of tuberculous infection occurring in a total hip replacement (THR).

\section{Case report}

An 86-year-old man presented with pain in the groin ten years after a successful primary THR for osteoarthritis (OA). He had been diagnosed with a papillary tumour in the bladder ten months previously and the lesion had been treated by transurethral resection and intravesicular chemotherapy with $80 \mathrm{mg}$ of epirubicin (Pharmorubicin; Pfizer, New York City, New York). Two months after surgery, weekly treatment with intravesicular Bacille-CalmetteGuérin (BCG) (Onco-Tice; Organon, Kenilworth, New Jersey) had been started for a period of six weeks. After an interval of three months without treatment, he had a course for another three weeks, giving a total of nine intravesicular instillations. During the final six months of treatment, he had experienced increasing pain in the groin, especially when bearing weight on his THR and rotating the hip. Other than his bladder cancer, he was healthy, with a high level of activity including trekking, boat renovation and extensive gardening.

A radiograph showed an Exeter (StrykerHowmedica, Kalamazoo, Michigan) cemented THR with radiolucent lines around the acetabular component and a fracture of the femoral cement mantle (Fig. 1).

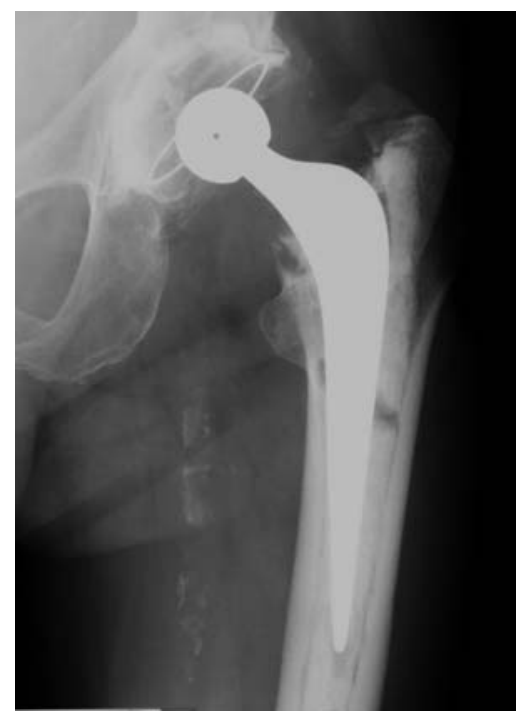

Fig. 1

Anteroposterior radiograph showing the Exeter total hip replacement with radiolucent lines around the acetabular component and fracture of the cement mantle. 


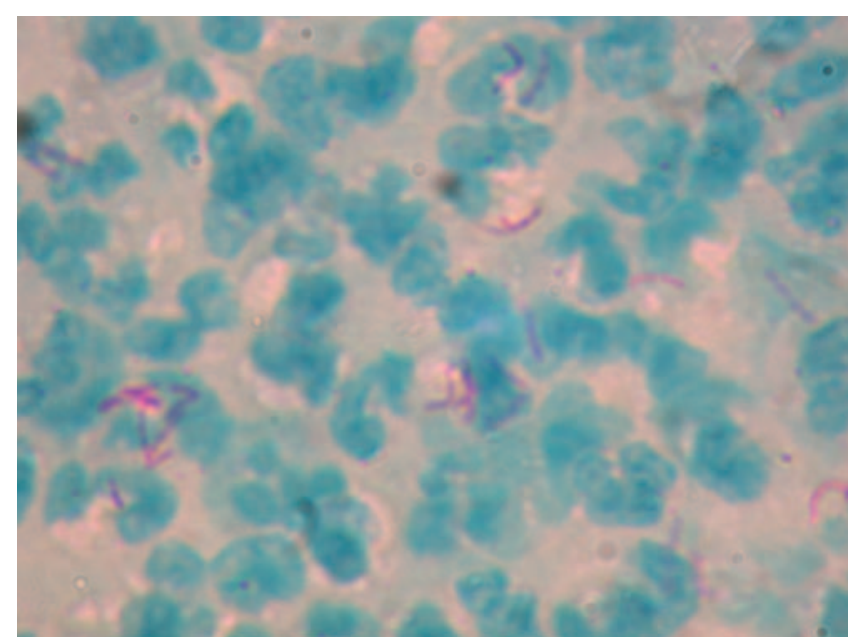

Fig. 2

Photomicrograph showing acid-resistant bacillae (acid resistant microbacterium bovis, magnifiction $\times 1000)$.

We decided to perform a revision THR using uncemented components. Pre-operative blood tests were within the normal range except for the ESR, which was marginally elevated at $18 \mathrm{~mm} /$ hour (normal level 3 to 16) and the level of C-reactive protein (CRP) at $12 \mathrm{mg} / \mathrm{l}$ (normal level 0 to 12).

After incising the capsule, approximately $50 \mathrm{ml}$ of thin watery yellowish pus was drained. Fluid and tissue biopsies were obtained and sent for culture and histological examination. Given the advanced age of the patient, we decided peroperatively to undertake a one-stage revision with implantation of an uncemented THR using a Kar (Depuy, Warsaw, Indiana) femoral component with a $28 \mathrm{~mm}$ chrome-cobalt head and a Trilogy (Zimmer, Warsaw, Indiana) acetabular component.

Sixteen days after operation, acid-fast bacilli were cultured and demonstrated histologically (Fig. 2). No other organisms were found.

Extensive investigation of the infecting organism using polymerase chain reaction (PCR), hybridisation and characterisation of the strain revealed that the Onco-Tice BCG strain used in the treatment of the superficial bladder carcinoma had been the causative organism of the infection. The sensitivities were confirmed and triple antituberculous treatment was started using rifampicin $(600 \mathrm{mg})$, isoniazid (300 $\mathrm{mg}$ ) and pyrazinamid (1.5 g) daily. The patient was mobilised and discharged after ten days. At six weeks after operation the erythrocyte sedimentation rate, C-reactive protein and white blood cell count were normal. Urine culture had failed to demonstrate tuberculosis, and cystoscopy and chest radiography were normal. After six months, the treatment was reduced to rifampicin and isoniazid, and then to isoniazid $(200 \mathrm{mg})$ daily in isolation after one year. After two years, all antibiotic treatment was discontinued.

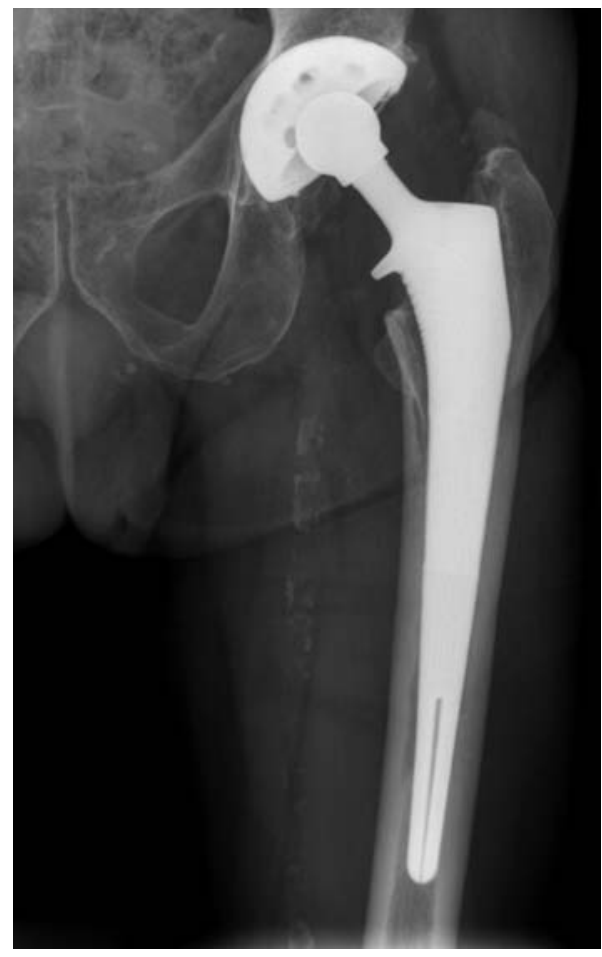

Fig. 3

Anteroposterior radiograph at 30 months follow-up after uncemented revision, showing a stable total hip replacement.

Post-operative radiographs at 3, 6, 12, 24 and 30 months (Fig. 3) showed a stable THR with increasing osseointegration and no lucencies.

The patient was able to tolerate the initial triple therapy without distress or disturbance of liver enzymes or renal function. He has remained free from pain and is mobile without crutches, returning to his former activities. At the final follow-up, his Harris hip score ${ }^{3}$ was 95 points.

\section{Discussion}

The weakened strain of living Mycobacterium bovis developed by Camille and Guérin in 19214 was intended for vaccination. The immunological effect through activation of the T-lymphocytes led to its use in the treatment of superficial bladder cancer in $1976 .{ }^{5}$

Intravesicular instillation of BCG and cytostatic medication at weekly intervals remain the principal treatment for non-invasive tumours. ${ }^{6,7}$ Side-effects comprise local irritation, immunological reactions, local infections and haematogenous septicaemia reported in almost every organ. ${ }^{8}$

Tuberculosis is one of the major diseases in the world, with approximately one third of the population infected, according to the World Health Organisation. ${ }^{2}$ The disease is attributable to three related organisms, mainly Mycobacterium tuberculosis, M. bovis and M. africanum. An increase in the number of serious cases is expected because 
of the emergence of multi-resistant strains of the bacterium and HIV infections.

Reports of BCG or M. tuberculosis infection in joint replacements are rare. Guerra et $\mathrm{al}^{9}$ reported a BCG infection in a THR in which revision to an excision arthroplasty was performed. After an interval of three months, following a six-month course of antituberculous treatment, a bone biopsy revealed acid-fast bacilli. The risk of re-infection was considered to be substantial and further reconstruction was not performed. Marmor, Parnes and Dekel ${ }^{10}$ reported three patients with tuberculous-infected knee replacements, in two of whom loosening had occurred. Treatment was successful with two-stage revision and antituberculous medication. The remaining patient was managed with lavage and antituberculous treatment. No sign of re-infection was seen at follow-up after 18 months and five and seven years. In contrast to other bacterial infections in joint replacements it seems that the mycobacterium does not produce a biofilm on implants. ${ }^{11}$ The main problem is the slow reproduction of the bacterium and the subsequent need for long periods of antibiotic treatment. ${ }^{12}$ The risks associated with one- or two-stage revision are acceptable if appropriate antibiotics are administered but treatment must be continued for a period of at least six months. Both Guerra et $\mathrm{al}^{9}$ and Marmor et $\mathrm{al}^{10}$ reported initial false-negative results from bacterial culture. It is important to consider this diagnosis, especially if sterile pus is present. Supplementary and prolonged culture of the samples can reveal unexpected results.
We are grateful to Dr B. Von der Lippe, Ulleval University Hospital, for his helpful advice on the management of this patient.

No benefits in any form have been received or will be received from a commercial party related directly or indirectly to the subject of this article.

\section{References}

1. Perdreau-Remington F, Stefanik D, Peters G, et al. A four-year prospective study on microbial ecology of explanted prosthetic hips in 52 patients with "aseptic" prosthetic joint loosening. Eur J Clin Microbial Infect Dis 1996;15:160-5.

2. WHO. Fact sheet No. 104 Tuberculosis. 2006. http://www.who.int/mediacentre/ factsheets/fs104/en (date accessed 12 December 2007).

3. Harris WH. Traumatic arthritis of the hip after dislocation and acetabular fractures: treatment by mold arthroplasty: an end-result study using a new method of result evaluation. J Bone Joint Surg [Am] 1969;51-A:737-55

4. Guérin C. The history of BCG. In: Rosenthal SR, ed. BCG vaccine: tuberculosis-cancer PSG: Littleton, 1980:35-43

5. Morales A, Eidinger D, Bruce AW. Intracavitary bacillus Calmette-Guerin in the treatment of superficial bladder tumors. J Urol 1976;116:180-3.

6. Martínez-Pineiro JA, Martínez-Pineiro L. BCG update: intravesical therapy. Eur Urol 1997;31(Suppl 1):31-41.

7. Witjes JA. Bladder carcinoma in situ in 2003: state of the art. Eur Uro/ 2004:45:142 6.

8. Gonzalez OY, Musher DM, Brar I, et al. Spectrum of bacille Calmett-Guerin (BCG) infection after intravesical BCG immunotherapy. Clin Infect Dis 2003;36:140-8.

9. Guerra CE, Betts RF, O'Keefe RJ, Shilling JW. Mycobacterium bovis osteomyelitis involving a hip arthroplasty after intravesicular bacille Calmette-Guerin for bladder cancer. Clin Infect Dis 1998;27:639-40.

10. Marmor M, Parnes $\mathbf{N}$, Dekel S. Tuberculosis infection complicating total knee arthroplasty: report of 3 cases and review of the literature. J Arthroplasty 2004;19:397-400

11. Ha KY, Chung YG, Ryoo SJ. Adherence and biofilm formation of Staphylococcus epidermidis and Mycobacterium tuberculosis on various spinal implants. Spine 2005;30:38-43

12. Frieden TR, Sterling TR, Munsiff SS, Watt CJ, Dye C. Tuberculosis. Lancet 2003;362:887-99 